\title{
REVIEW
}

\section{Preparing Pharmacy Educators as Expedition Guides to Support Professional Identity Formation in Pharmacy Education}

\author{
Jessica L. Johnson, PharmD, ${ }^{a}$ Sally Arif, PharmD, ${ }^{\mathrm{b}}$ Timothy J. Bloom, PhD, ${ }^{\mathrm{c}, \mathrm{d}}$ Alex N. Isaacs, PharmD, MS, ${ }^{\mathrm{e}}$ \\ Lindsey E. Moseley, PharmD, MEd, ${ }^{f}$ Kristin K. Janke, $\mathrm{PhD}^{\mathrm{g}}$ \\ ${ }^{a}$ William Carey University, School of Pharmacy, Biloxi, Mississippi \\ ${ }^{\mathrm{b}}$ Midwestern University, College of Pharmacy-Downers Grove, Downers Grove, Illinois \\ ${ }^{c}$ Shenandoah University, Bernard J. Dunn School of Pharmacy, Winchester, Virginia \\ ${ }^{\mathrm{d}}$ Editorial Board Member, American Journal of Pharmaceutical Education, Arlington, Virginia \\ ${ }^{\mathrm{e}}$ Purdue University, College of Pharmacy, West Lafayette, Indiana \\ ${ }^{\mathrm{f}}$ Auburn University, Harrison School of Pharmacy, Auburn, Alabama \\ ${ }^{\mathrm{g}}$ University of Minnesota, College of Pharmacy, Minneapolis, Minnesota
}

Corresponding Author: Jessica L. Johnson, William Carey University, School of Pharmacy, 19640 Hwy 67, Biloxi, MS 39532. Tel: 225-485-8602. Email: jejohnson@wmcarey.edu

Submitted October 29, 2021; accepted February 1, 2022; ePublished February 2022

Objective. To provide an educator-friendly travel guide for supporting professional identity formation (PIF) for pharmacy students.

Findings. In contrast to professionalism, which has emphasized externally visible behaviors, professional identity focuses on the internalization of the attitudes, standards, and behavioral norms of a profession, such that one "thinks, acts, and feels" like a member of that profession. Identity, whether personal or professional, is continuously developed in part during interactions with others and in response to internal and external feedback on those interactions. Educators play a critical role in helping students navigate the "provocative moments" (eg, transitions, dissonance) that accompany identity formation. To help educators travel with purpose, several identity formation theories suggest means of creating learning experiences and supporting the development of a professional identity. Additionally, guidebooks for the trip (ie, published literature) provide examples of didactic and experiential teaching approaches that can be used to promote PIF. While further exploration and research are necessary, traveling this journey with colleagues can help members of the Academy succeed in sustainably and effectively infusing intentional PIF within pharmacy education and training.

Summary. There are myriad ways for educators to develop and support PIF, which can present a challenge when defining the role that educators play in this complex, dynamic process. Educators must understand the reasoning behind various approaches and the common dialogue used, in order to engage and support learners as their expedition guides on the lifelong journey to professional identity formation.

Keywords: professional identity formation, professionalism, socialization, communities of practice

\section{INTRODUCTION}

\section{Embracing The Expedition}

Professional identity formation (PIF) is critical to supporting practice transformation and is being established as a goal of modern health professions education. 'Medical education has defined professional identity as "a representation of self, achieved in stages over time during which the characteristics, values, and norms of the medical profession are internalized, resulting in an individual thinking, acting, and feeling like a physician." ${ }^{2}$ However, another description, less specific to physician training, is provided in a report by Cooke and colleagues as a "moral and ethical core of service and responsibility around which habits of mind and practice could be organized." In their 2010 description of the need for reform of medical education, Cooke and colleagues explain how development of professional values and aspirations supports affective educational goals of performance excellence, accountability, humanism, and altruism. In concert with other leaders in health care education reform, they call for professional curricula to integrate the cognitive and moral aspects of practice, as students are challenged with developing both technical competence and deeply ingrained moral responsibility. ${ }^{13}$ Monrouxe further suggests it is essential for students to develop and embrace a professional identity during their training, as this allows for internal professional regulation supporting educational goals of self-directed, lifelong learning. ${ }^{4}$ 
There are additional benefits to a focus on identity. Pharmacists today face a professional imperative to address challenges in the health care system through practice transformation. A programmatic focus on professional identity can help students envision the scope and nature of pharmacists' work as including change agency. A strong professional identity helps students to confidently explain, present and conduct themselves and collaborate interprofessionallys as they continue to advocate for expanded roles for pharmacists.

Yet, a decision by members of the American Association of Colleges of Pharmacy (the Academy) to intentionally support PIF ${ }^{6.7}$ comes with challenges and questions. Why should PIF be a priority in my teaching? Am I prepared to guide and support students in their PIF journey? What do I need to know about the process of PIF? What actions do I take with individual learners? How do I better understand the progress students are making?

The purpose of this paper is to provide an educator-friendly guide to "getting started with PIF," in order to bolster support for PIF within the Academy. Specifically, this paper introduces PIF examples, theories, and definitions to begin preparing educators to serve as tour guides for students on their PIF journey. As authors, we envision students' development of professional identity as a journey of self-discovery and employ a "traveling" metaphor to aid readers in relating to the challenges and complexities inherent to this life-long journey. We encourage educators to explore and adapt these approaches while planning their own students' PIF excursions. Nonetheless, it is important to remember there is no single, clear path to PIF, and some road bumps and diversions requiring redirection along the way should be expected.

\section{Embarking On A Continuous Journey}

Supporting the transformation of a layperson into an individual who can "think, act, and feel" like a pharmacist 2 is a challenging and complex task requiring repeated, diverse, and intentional pedagogical approaches throughout training and professional practice. This professionalization is a dynamic, lifelong, social and educational process shaped through formal and informal interactions, experiences, and relationships with others. ${ }^{8.9}$ All educators, administrators, preceptors, and student services professionals contribute to PIF, positively or negatively, knowingly or otherwise, through attitudes, expectations, interactions, and activities throughout the curriculum and co-curriculum. ${ }^{10}$

There are many student, educator, and environmental conditions to consider when implementing and refining feasible, sustainable, and high-impact approaches to deliberately support student PIF in ways that fit an institution's culture and mission. Educators are encouraged, over time, to find traveling companions who bring creativity, curiosity, adaptability, and responsiveness to expand and enhance work in this area. While partners, teamwork, and PIF-focused curricular approaches are goals, individual educators can begin with initial, small-scale efforts to make progress on the path towards larger milestones. Though some may argue that professionalization occurs naturally within modern pharmacy curricula, careful planning, including choice of companions and route, increases the likelihood of meaningful and enjoyable progression towards PIF for travelers.

\section{Traveling With Purpose}

Despite a widespread emphasis in pharmacy curricula on teaching professionalism guided by Standards 2016", Hammer and colleagues have expressed concern "that acting professionally is not the same as being a professional." Though educators use a variety of assessment tools to "check-off" professionalism competencies, students may fail to internally adopt the values, commitments, and dispositions of the profession. Intentional and widespread curricular emphasis on PIF as a purposeful extension of professionalism training may serve to help students internalize desired characteristics and traits as they adapt to the role of pharmacist and solidify their professional identity. ${ }^{1.13}$

Identity can be described as the way in which one is defined by oneself and others. ${ }^{14}$ In order to make sense of their own personal situations, individuals construct and modify identities by drawing on, engaging with, and accepting community norms and practices. ${ }^{14}$ Identity formation is a complex, longitudinal interplay between the individual and others in their social network, and in part, on the roles one is expected or allowed to take. Personal identity formation is initiated during childhood and continues throughout adulthood as interactions with family and friends, educational culture and environment, societal expectations, and feedback from others stimulate change. . $9.15^{15}$ According to the Multiple Dimensions of Identity theory, several identity components may be developing concurrently within the same individual, as they engage in multiple communities specific to their, for example, profession, hobbies, religion, and sexual orientation. ${ }^{16}$ Similarly, developing a professional identity involves social interactions, but also reflecting and acting on feedback as one's roles and responsibilities within the professional community evolve [Figure 1]. Cruess and colleagues suggest that the professional identity must be compatible and coexist with personal identities for each to be strong. The strength and compatibility of these many and diverse identities are critical to personal and professional wellbeing.

Jarvis-Selinger and colleagues propose that identity progression is precipitated by a "crisis" that requires change or growth as a response. ${ }^{15}$ This crisis can be thought of as a stressful event that precipitates learning and adaptation as a stress response. Physicians have long considered their first cadaver encounter and first patient death as milestone 
experiences and powerful opportunities for reflective growth shared by all physicians. ${ }^{2}$ However, other types of seemingly insignificant crises, such as being called upon to answer questions in class, or administering an intramuscular injection to a patient, can also present potential opportunities for PIF. ${ }^{17}$ How well an individual navigates these crises determines, in part, the influence of that experience on the individual's identity.

The identification or manufacture of suitable "academic crises" will therefore be a critically important role for educators, who are specifically responsible for managing the learning environment in ways that optimize the likelihood that learning will occur. Rudland and colleagues suggest that health professions educators can best support students' learning journey by managing the type and amount of stressors experienced by students. ${ }^{17}$ For example, educators should strive to avoid intentionally distressing events or environments that can hinder engagement, learning, and growth. To some extent, we do this by managing course loads and exam schedules, providing strong student services and counseling support, and role-modeling positive social norms and behaviors. However, eustress is thought to support positive outcomes for learners and may have similar implications for identity formation. ${ }^{17}$ Eustress is a beneficial form of stress that optimizes attention, motivation, and performance; in essence, stress created by a challenge considered achievable. For example, a clinical educator could scaffold a learning experience to provide supervised autonomy, when appropriate, for the student pharmacist to lead clinical encounters with patients or other health care providers. Students may experience some stress given the instructor's expectations of leadership, but learning often occurs in response to such circumstances, so long as the learner interprets the situation as a challenge and not a threat. ${ }^{17}$ Educators can aid students in interpreting and responding to these challenges in beneficial ways such that these provocative learning "crises" can enhance confidence and advance student PIF. Ideally, pharmacy educators will find ways to create authentic situations that force students to think like a pharmacist and act like a pharmacist with the intent of leading students to feel like a pharmacist.

\section{Consulting Guidebooks}

As the foundation for evidence-based scholarly teaching, health professions educators are often asked to use theory, which, by definition, provides "a description of the relationships between concepts that help us to understand the world." ${ }^{18}$ Theories can act as a lens, providing clarity and perspective when designing interventions and interpreting outcomes. ${ }^{19}$ Because theory can be dense and difficult to decipher, educators sometimes resort to incorporating theory only during the manuscript development stages of a scholarly project. However, explicit use of PIF-related theories in the early stages of instructional design can increase efficiency by providing direction and focus, which in turn can increase the coherence, depth, validity, intentionality, and effectiveness of learning activities. . $18.19^{19}$

Noble and colleagues review the extrapolation of personal identity formation theories to PIF by researchers in pharmacy, nursing, and medical education..$^{20}$ Many identity theories exist in harmony with one another with each seeking to understand some particular or unique aspect of identity formation or cohesion. As a result, one particular theory cannot be universally recommended over another. Rather, educators wishing to engage in PIF pedagogy should develop a theoretical framework that logically melds the concepts and premises from one or more theories to structure PIF initiatives. ${ }^{18}$ The paragraphs that follow summarize several theories that educators may find helpful in designing excursions for student travelers. Considering the apparent convergence between existing theories previously applied to health professions education and newly emerging explorations, ${ }^{21}$ educators can emphasize application of existing theories of identity formation rather than prioritizing the discovery or development of novel approaches.

These theories are not mutually exclusive and many describe different aspects or perspectives on similar and interrelated concepts. For example, the Communities of Practice ${ }^{22}$ model and Social Identity Theory ${ }^{23}$ both describe how individuals slowly integrate into a group by participating in the group's activities and rely on feedback from the group to influence their identity as a member of that group. [Table 1] Intuitive and well-established, Communities of Practice is already widely applied to health professional education. Likely to be understood by many students and educators, Communities of Practice offers a sound and relatable description of the mechanisms by which curricular, co-curricular, and experiential education activities lead to the adoption of identity. Thus, some experts advocate for exclusive and widespread adoption of the Communities of Practice model in health professions education. ${ }^{9}$

However, other established theories of identity formation are equally compelling and offer some advantages over Communities of Practice, which is a system-focused description of socialization of individuals into a group.[Table 2] SelfAuthorship Theory ${ }^{24}$, for example, is a more holistic and person-centered theory describing an individual's advancement through four distinct phases of identity maturity, potentially leading to opportunities to assess student progression over time. ${ }^{25}$ While the possibility of identity formation assessment is attractive to many educators and administrators, SelfAuthorship theory's strongest value may be its focus on pivotal "provocative moments" (similar to "crises" described above). Additionally, Baxter-Magolda provides strong pedagogical support for the development of Self-Authorship through the Learning Partnership Model $^{24}$, which offers explicit guidance to educators seeking to design learning experiences that can potentially generate provocative moments for students [Table 2]. These conditions and requirements 
can be utilized by educators as guidelines for the manufacture of the kinds of crises and learning experiences that route travelers just far enough out of their comfort zones to require them to adapt, potentially resulting in progress in their PIF journey. ${ }^{26}$

An educator's choice of a guiding theory involves considering the theory's ability to explain the relationships between variables of interest. For instance, when constructing social activities, Social Identity or Communities of Practice theories may be helpful in considering issues of belonging or participation. On the other hand, optimizing activities that focus on the individual may benefit from either Self-Authorship or Provisional Selves theory ${ }^{27}$, which provide guidance on supporting internal transitions or the role of experimentation in identity formation. In fact, educators can consider drawing on multiple relevant theories to scaffold or guide their work in this area. ${ }^{18}$ Although many travelers delight in spontaneous, unscripted, and off-road adventures, deliberate and intentional scholarly teaching maximizes learning for the students involved. Regardless of which guidebook(s) an educator chooses, the experiences and insights of previous travelers are invaluable strategic planning assets.

\section{New Excursions In Familiar Locations}

Table 3 illustrates three PIF-building examples for educators training health-professions students in various environments. Educators may be relieved to know that useful, PIF-friendly pedagogies (eg, reflective writing ${ }^{28}$, interactions with others ${ }^{29}$, and mentoring and positive role modeling ${ }^{30}$ ) are already embedded in many classrooms and familiar learning environments, but activities may need some modification to more intentionally facilitate PIF. The exact modifications that can stretch an activity from teaching professionalism to supporting professional identity formation are open for further exploration, though some specific reports have been published. For example, intentionally designed narratives and guided reflective assignments can provide students with the opportunity to make sense of their experiences and develop their professional identity. ${ }^{42,631}$

The typical goal of PIF pedagogy is to help students internalize the meaning of an experience, in order to develop an identity that aligns with the values of the profession. Educators, including administrators and student services professionals, can all serve as role models and facilitators of the human and emotional dimensions of the learner's experience and can lead mentoring conversations that explore meaningful themes of integrity, meaning, resilience, and well-being. ${ }^{32}$ In particular, they can help learners to navigate transitions (eg, pre-pharmacy to pharmacy, shadowing to care provision) and process crises and provocative moments (eg, patients resisting advice despite dire consequences). Educators can also assist students in integrating their personal and professional identities by guiding conscious, collaborative, reflection with individuals or small peer groups and by creating environments that allow students to freely and safely discuss vulnerabilities, self-doubts, ethical dissonances, and progress. . $6.32 .33^{2}$ In addition, educators can help student pharmacists learn the language of the profession and the language of health care, as well as learning to maneuver within the hierarchies and power relationships that facilitate, and potentially inhibit, the role of the pharmacist. Finally, educators can support students as they "play the role" on their way to being a pharmacist, specifically by identifying and helping students process the emotions (eg, anxiety, frustration, satisfaction, pride) that may ensue during their travels [Figure 1]. ${ }^{34}$

It is important for educators and mentors to not only create experiences that promote socialization and a sense of belonging within the profession, but also provide the student with feedback regarding areas of improvement and validation of their beliefs and behaviors related to the pharmacist role. ${ }^{8.35}$.Educators and mentors should provide feedback that helps learners develop confidence and to eventually become their own source of feedback. ${ }^{36}$ Formative feedback from mentors is typically immediate and informal, intended to provide insight about the learner's motives and actions in a given experience and the consequences of those behaviors on a student's transition from layperson to pharmacist. An educator's feedback may be more delayed, and when given as a grade may be seen as more formal, but when done well also supports the student's skill at self-monitoring. This type of iterative, constructive feedback aids learners in reinforcing strengths, identifying and correcting weaknesses, and practicing desired behaviors. ${ }^{37}$ It is the reinforcement of these desired behaviors, through formative feedback from other professionals, that eventually leads to adoption and ingrainment of the professional identity.

PIF is an emotion-packed and potentially unnerving adventure. Just as a debriefing conversation with a colleague can help travelers process their experiences, students benefit from dialogue and support in making meaning of formative moments in their PIF journey. Although supporting PIF may seem exotic and foreign to educators, there are ways to adapt familiar strategies toward a more explicit PIF focus.

\section{Navigating Less-Charted Territory}

Assessment of professional identity formation in students has been largely formative and is thus less welldocumented. This is for practical reasons because, as Crossley and Vivekananda-Schmidt argue, the only person who can 
meaningfully gauge a subject's self-identity is the subject themselves. ${ }^{38}$ Within experiential training, learning logs (ie, entries about patient interactions) have been used to deepen learning and develop self-awareness by asking students to record observations they considered important, interesting, impressive, difficult, distressing or significant. ${ }^{39}$

Documentation of these provocative moments or crises can then be reviewed by educators and discussed with learners, providing formative feedback and aiding in the self-reflection and meaning-making required for identity formation. More work is needed to understand the types of formative assessments that provide useful feedback to both the guide and to the traveler. Similarly, the influence of various forms of reflective exercises supporting identity formation, and helping to resolve identity dissonance, merits further investigation.

Summative evaluations, including surveys and attempts to classify an individual's identity status have also been explored in research studies. For example, a Professional Self-Identity Questionnaire (PSIQ) has been developed "as a research tool to understand the curricular features that contribute to the development of professional self-identity." ${ }_{38}$ While this tool is not intended to analyze professional identity or as an individual assessment, it may be useful in self-reflection and self-monitoring. Pharmacy was not considered in the development of this tool, but it has since been used to examine the influence of pre-matriculation pharmacy experience on professional identity formation in pharmacy students..$^{40}$

Other researchers have used commitment to the profession (ie, degree of personal investment) and exploration (ie, trying on identities during a period of reflection) as variables in attempting to classify occupational identity status (ie, a characteristic way of dealing with the salient identity issues). ${ }^{41,42}$ For example, in medical education, Niemi examined student reflections to describe four identity statuses of pre-clinical students: diffuse identity status, vague fantasies and tentative ideas, active exploration of specific alternatives, and achieved professional identity. ${ }^{39}$ Narrative approaches (ie, tapping into the inner world of the individual as a conscious decision-maker in their personal story) and discursive approaches (ie, examining the roles of talk, interaction and language in identity formation) have also been used to examine identity formation. ${ }^{41}$

Though pharmacy educators seek to better understand personal trajectories in PIF and curricular influences, identity research indicates that development changes cannot be detected over short periods of time. ${ }^{42}$ Development of professional identity is likely influenced by proactivity, a strong sense of agency, adaptive personality characteristics and a host of other personality factors. ${ }^{42}$ Future work in identity strength and identity achievement should consider timeframe (especially longitudinal studies), personality characteristics, social and cultural contexts, the influence of family and peers, as well as the influence of various identity formation pedagogies and interventions. Work in PIF assessment may be similar to exploration and discovery; there are few maps and no guaranteed safe and timely arrivals. Anticipate the need for formative assessment approaches and attempt to share your results with other PIF-interested educators.

\section{Reviewing Your Passport Stamps}

Educators will accumulate PIF-related experiences over time that aid their effectiveness in guiding the journey of others. Prior to offering such assistance, it is important for educators to embrace the intentional, and sometimes uncomfortable, first step of self-reflection. Introspective, PIF-focused professional development efforts enable educators to identify and reflect on their own multiple personal and professional identities (practitioner, educator, parent, etc.), including those in conflict. ${ }^{43}$ Specific activities that may benefit educators should be founded in PIF theory and could include: evaluation of published literature, reflective writing, and small group discussions regarding personal insights and self-reflection. Such experiences can be foundational in helping educators to understand PIF within themselves prior to facilitating it within learners. ${ }^{43}$

Introspective questions for educators to ask ourselves: How would I describe my personal and professional identities? Which experiences and individuals have been important influences on my values, attitudes and beliefs as a professional? What dissonance have I experienced in my identity as an Educator? Pharmacist? Scholar? Which of my identities did I feel most or least comfortable expressing during my education or training?

Colleges and Schools of Pharmacy are encouraged to support and prepare educators to be role models and facilitators of PIF within pharmacy learners. Effective faculty development programming, whether one-time or longitudinal events, will likely require identification of a local "PIF champion" within the institution or organization. These PIF faculty development seminars can assist educators in reflecting on the formation of their own personal and professional identities, provide an overview of the nature of identity formation, and contribute to an understanding of socialization. ${ }^{43-47}$ Faculty development programming can also assist basic scientists in learning from pharmacy practitioners what it means to "think, act, and feel" like a pharmacist. Finally, faculty development programming can facilitate dialogue around existing PIF initiatives and enable collaboration for curricular integration of PIF components within an institution. Joining local and national professional development communities can support educators in their own identity formation, but also enable and allow educators to model vulnerability with others, much as they will be requesting of learners in future PIF initiatives. ${ }^{43,46}$ 
Traveling can broaden one's mind. From the outset, reflectively consider your own formative excursions and their value to you as a guide now charged with supporting others new to the road. Preparing yourself can make the journey more impactful for yourself and your learners.

\section{Choosing Travel Companions}

Developing PIF activities in a course or experiential rotation may seem daunting, especially when setting out alone. As with other aspects of pharmacy education, this is not a task that ought to be done in a silo. The 2019-2020 AACP House of Delegates adopted the following policy statement proposed by the 2019-2020 Student Affairs Committee $:$

"AACP encourages colleges and schools of pharmacy to advance education that is aimed at the intentional formation of professional identity (ie, thinking, feeling and acting like a pharmacist) and developed and implemented in cooperation with professional pharmacy organizations within the broader pharmacy profession."”。

This is an ambitious goal that will require a strong vision and core group of early adopters. ${ }^{7}$ For program-level implementation, institutional support will also be needed. As described by Cruess et al, "deans and chairs must publicly signal their approval and institute measures that lead to faculty buy-in." Developing a program-level PIF approach also requires the identification of an end point towards which the program is working-the professional identity that educators are helping to form in their students. ${ }^{48}$ Just as one's personal and professional identities must be compatible, the professional identity that a program targets will need to be compatible with the School or College's mission and local practice standards. As successes drive the growth of efforts beyond the initial work, additional faculty development, support and coordination will be needed to implement activities widely and longitudinally within a curriculum.

Ultimately, a larger scale, intentionally-designed effort will be needed to support students in and through various phases of their development. ' Curriculum and student affairs committees will be integral to curricular changes needed to optimize the PIF programming, while assessment professionals may have knowledge of or access to data useful in understanding student progress. Student services professionals, often trained in identity formation, may be particularly helpful and/or interested in this work. As with many new initiatives, benefit can be derived from within-institution (eg, PIF as part of interprofessional education) and across-institution sharing and joint initiatives (eg, multi-institutional implementation and evaluation of a pedagogical approach). Remember, short trips might be managed on your own, but a major journey like that of identity formation requires support and cooperation from others with unique and diverse expertise. Identify companions who can aid you in instructional design to collaboratively develop and evaluate opportunities for formative moments that are as memorable and meaningful to students as possible.

\section{CONCLUSION}

Educators and learners are fellow voyagers on the lifelong professional identity expedition. As educators knowingly or unknowingly exert influence on the development of professional identity of learners, so too do learners impact the PIF of educators. This reciprocity couples with the unpredictable routes and destination of identity development to facilitate an exciting PIF adventure.

Because PIF groundwork is initiated within existing learning activities, identifying, expanding and focusing those experiences is needed for a meaningful and lasting imprint. There is no singular method by which educators support PIF, which can present a challenge, but also provides educators the freedom to creatively infuse this complex, dynamic process into existing learning experiences.

PIF is critical to practice transformation, as it strengthens and enables agents for change within the profession of pharmacy. PIF can occur naturally, but to develop it reliably and efficiently in all learners requires dedicated efforts by faculty and planned initiatives by a PharmD program. While long-term goals for the Academy include strategic curricular implementation of PIF programming, individual educators can support the movement with grassroots initiatives. To get started, educators must begin exploring the reasoning and dialogue behind PIF, as well as their own experiences in professional identity. Each step in the PIF journey, regardless of how small, is a step in the right direction.

\section{REFERENCES}

1. Cooke, M., Irby, D. M., O'Brien, B. C. Educating Physicians: A Call for Reform of Medical School and Residency. San Francisco, CA: Jossey-Bass; 2010.

2. Cruess RL, Cruess SR, Boudreau JD, Snell L, Steinert Y. Reframing medical education to support professional identity formation. Acad Med. 2014;89(11):1446-1451. doi:10.1097/ACM.0000000000000427 
3. Frenk J, Chen L, Bhutta ZA, et al. Health professionals for a new century: Transforming education to strengthen health systems in an interdependent world. Lancet. 2010;376(9756):1923-1958. doi:10.1016/S01406736(10)61854-5

4. Monrouxe L V. Identity, identification and medical education: why should we care? Med Educ. 2010;44(1):40-49. doi:10.1111/j.1365-2923.2009.03440.x

5. Cantillon P, Dornan T, De Grave W. Becoming a clinical teacher. Acad Med. 2019;94(10):1610-1618. doi:10.1097/acm.0000000000002403

6. Welch BE, Arif SA, Bloom TJ, et al. Report of the 2019-2020 AACP student affairs standing committee. Am J Pharm Educ. 2020;84(10):1402-1408. doi:10.5688/ajpe8198

7. Janke KK, Bloom TJ, Boyce EG, et al. A pathway to professional identity formation: report of the 2020-2021 AACP student affairs standing committee. Am J Pharm Educ. 2021. Published online July 2021. doi:10.5688/ajpe8714

8. Goldie J. The formation of professional identity in medical students: considerations for educators. Med Teach. 2012;34(9):e641-8. doi:10.3109/0142159X.2012.687476

9. Cruess SR, Cruess RL, Steinert Y. Supporting the development of a professional identity: General principles. Med Teach. 2019;41(6):641-649. doi:10.1080/0142159X.2018.1536260

10. Joynes VCTT. Defining and understanding the relationship between professional identity and interprofessional responsibility: implications for educating health and social care students. Adv Heal Sci Educ. 2018;23(1):133149. doi:10.1007/s10459-017-9778-x

11. Accreditation Council for Pharmacy Education. Accreditation standards and Key Elements for the professional program in pharmacy leading to the doctor of pharmacy degree. Chicago, Ill: ACPE; 2015; https://www.acpeaccredit.org/pdf/ Standards2016FINAL.pdf

12. Hammer DP, Berger BA, Beardsley RS, Easton MR. Student professionalism. Am J Pharm Educ. 2003;67(3):129.

13. Cruess RL, Cruess SR, Steinert Y. Amending Miller's pyramid to include professional identity formation. Acad Med. 2016;91(2):180-185. doi:10.1097/ACM.0000000000000913

14. Frost HD, Regehr G. I am a doctor: negotiating the discourses of standardization and diversity in professional identity construction. Acad Med. 2013;88(10):1570-1577. doi:10.1097/ACM.0b013e3182a34b05

15. Jarvis-Selinger S, Pratt DD, Regehr G. Competency is not enough: integrating identity formation into the medical education discourse. Acad Med. 2012;87(9):1185-1190. doi:10.1097/ACM.0b013e3182604968

16. Jones SR, McEwen MK. A conceptual model of multiple dimensions of identity. J Coll Stud Dev. 2000;41(4):405-414.

17. Rudland JR, Golding C, Wilkinson TJ. The stress paradox: how stress can be good for learning. Med Educ. 2020;54(1):40-45. doi:10.1111/medu.13830

18. Varpio L, Paradis E, Uijtdehaage S, Young M. The distinctions between theory, theoretical framework, and conceptual framework. Acad Med. 2020;95(7):989-994. doi:10.1097/ACM.0000000000003075

19. Collins CS, Stockton CM. The central role of theory in qualitative research. Int J Qual Methods. 2018;17(1):110. doi:10.1177/1609406918797475

20. Noble C, McKauge L, Clavarino A. Pharmacy student professional identity formation: a scoping review. Integr Pharm Res Pract. 2019;8:15-34. doi:10.2147/IPRP.S162799

21. Quinn G, Lucas B, Silcock J. Professional identity formation in pharmacy students during an early preregistration training placement. Am J Pharm Educ. 2020;84(8):1132-1139. doi:10.5688/ajpe7804

22. Wenger, E. Communities of Practice: Learning, Meaning, and Identity. Cambridge, UK: Cambridge University Press; 1998.

23. Tajfel, H. The achievement of inter-group differentiation. In: Breakwell G, Brown R, Tajfel H, eds. Differentiation Between Social Groups: Studies in the Social Psychology of Intergroup Relations. United Kingdom: European Association of Experimental Social Psychology by Academic Press, 1978: pgs 77-100.

24. Baxter Magolda, M. Making Their Own Way: Narratives for Transforming Higher Education to Promote SelfDevelopment. Sterling, VA: Stylus publishing; 2001.

25. Creamer EG, Magolda MB, Yue J. Preliminary evidence of the reliability and validity of a quantitative measure of self-authorship. J Coll Stud Dev. 2010;51(5):550-562. doi:10.1353/csd.2010.0010

26. Johnson JL, Chauvin S. Professional identity formation in an advanced pharmacy practice experience emphasizing self-authorship. Am J Pharm Educ. 2016;80(10):Article 172. doi:10.5688/ajpe8010172

27. Ibarra H. Provisional selves: Experimenting with image and identity in professional adaptation. Adm Sci $Q$. 1999;44(4):764-791. doi:10.2307/2667055 
28. Yakov G, Riskin A, Flugelman AA. Mechanisms involved in the formation of professional identity by medical students. Med Teach. 2021;43(4):428-438. doi:10.1080/0142159X.2020.1854706

29. White MT, Borges NJ, Geiger S. Perceptions of factors contributing to professional identity development and specialty choice: a survey of third- and fourth-year medical students. Ann Behav Sci Med Educ. 2011;17(1):1823. doi:10.1007/bf03355144

30. Rabow MW, Remen RN, Parmelee DX, Inui TS. Professional formation: extending medicine's lineage of service into the next century. Acad Med. 2010;85(2):310-317. doi:10.1097/ACM.0b013e3181c887f7

31. Clandinin DJ, Cave M-T. Creating pedagogical spaces for developing doctor professional identity. Med Educ. 2008;42(8):765-770. doi:10.1111/j.1365-2923.2008.03098.x

32. Chandran L, Iuli RJ, Strano-Paul L, Post SG. Developing "A Way of Being”: deliberate approaches to professional identity formation in medical education. Acad Psychiatry. 2019;43(5):521-527. doi:10.1007/s40596019-01048-4

33. Cruess RL, Cruess SR, Steinert Y. Medicine as a community of practice: implications for medical education. Acad Med. 2018;93(2):185-191. doi:10.1097/ACM.0000000000001826

34. Cruess RL, Cruess SR, Boudreau JD, Snell L, Steinert Y. A schematic representation of the professional identity formation and socialization of medical students and residents. Acad Med. 2015;90(6):718-725. doi:10.1097/ACM.0000000000000700

35. Wald HS. Professional identity (trans)formation in medical education: reflection, relationship, resilience. Acad Med. 2015 Jun;90(6):701-6. doi: 10.1097/ACM.0000000000000731.

36. Cruess SR, Cruess RL. The development of professional identity. In: Understanding Medical Education. John Wiley \& Sons, Ltd; 2018:239-254. doi:10.1002/9781119373780.ch17

37. Weitzel KW, Walters EA, Taylor J. Teaching clinical problem solving: a preceptor's guide. Am J Health Syst Pharm. 2012 Sep 15;69(18):1588-99. doi: 10.2146/ajhp110521.

38. Crossley J, Vivekananda-Schmidt P. The development and evaluation of a Professional Self Identity Questionnaire to measure evolving professional self-identity in health and social care students. Med Teach. 2009;31(12):e603-e607. doi:10.3109/01421590903193547

39. Niemi PM. Medical students' professional identity: self-reflection during the preclinical years. Med Educ. 1997;31(6):408-415. doi:10.1046/j.1365-2923.1997.00697.x

40. Bloom TJ, Smith JD, Rich W. Impact of pre-pharmacy work experience on development of professional identity in student pharmacists. Am J Pharm Educ. 2017;81(10):87-92. doi:10.5688/ajpe6141

41. Monrouxe L V, Rees CE. Theoretical perspectives on identity: researching identities in healthcare education. In: Cleland JA, Durning SJ, eds. Researching Medical Education. John Wiley \& Sons, Ltd; 2015:129-140. doi:10.1002/9781118838983.ch12

42. Skorikov VB, Vondracek FW. Occupational identity. In: Schwartz SJ, Luyckx K, Vignoles VL, eds. Handbook of Identity Theory and Research. Springer New York; 2011:693-714. doi:10.1007/978-1-4419-7988-9

43. van Lankveld T, Thampy H, Cantillon P, Horsburgh J, Kluijtmans M. Supporting a teacher identity in health professions education: AMEE Guide No. 132. Med Teach. 2021;43(2):124-136. doi:10.1080/0142159X.2020.1838463

44. Steinert Y, Boudreau JD, Boillat M, et al. The osler fellowship: an apprenticeship for medical educators. Acad Med. 2010;85(7):1242-1249. doi:10.1097/ACM.0b013e3181da760a

45. Steinert Y, O’Sullivan PS, Irby DM. Strengthening teachers' professional identities through faculty development. Acad Med. 2019;94(7):963-968. doi:10.1097/ACM.0000000000002695

46. O'Sullivan PS, Steinert Y, Irby DM. A faculty development workshop to support educator identity formation. Med Teach. 2021;0(0):1-2. doi:10.1080/0142159X.2021.1921135

47. Armitage-Chan E, May SA. Developing a professional studies curriculum to support veterinary professional identity formation. $J$ Vet Med Educ. 2018;45(4):489-501. doi:10.3138/jvme.1216-192r1

48. Dawodu P, Rutter P. How do pharmacists construct, facilitate and consolidate their professional identity? Pharmacy. 2016;4(3):23. doi:10.3390/pharmacy4030023 


\begin{tabular}{|c|c|c|c|c|c|}
\hline $\begin{array}{c}\text { Identity Formation } \\
\text { Theories }\end{array}$ & Foundational Concepts & Trigger/Stimulus & End Goal & Application in PIF & Benefits/Limitations \\
\hline $\begin{array}{l}\text { Explores the question: } \\
\text { "How does } \\
\text { participation or } \\
\text { involvement in a } \\
\text { social group influence } \\
\text { an individual?" }\end{array}$ & $\begin{array}{l}\text { Communities of Practice } \\
\text { theory describes how people } \\
\text { continuously create a shared } \\
\text { identity through engaging in } \\
\text { and contributing to a } \\
\text { community. Legitimate } \\
\text { peripheral participation in a } \\
\text { community socializes an } \\
\text { individual to eventual full } \\
\text { participation and membership } \\
\text { within that community. Each } \\
\text { individual's contribution } \\
\text { shapes the community and the } \\
\text { community in return shapes the } \\
\text { individual's identity. }\end{array}$ & $\begin{array}{l}\text { In this model, } \\
\text { observation is not } \\
\text { included as a means of } \\
\text { developing identity. } \\
\text { Active participation, no } \\
\text { matter how small, is } \\
\text { required. Increasing } \\
\text { competence in the } \\
\text { practice area of the } \\
\text { community is rewarded } \\
\text { with increased } \\
\text { responsibility within the } \\
\text { community, and } \\
\text { therefore stronger } \\
\text { identity as a member of } \\
\text { the community. }\end{array}$ & $\begin{array}{l}\text { Legitimate participation } \\
\text { in a group that allows for } \\
\text { ego, belonging, and skill } \\
\text { development through } \\
\text { practice. } \\
\text { According to Dr. Wenger, } \\
\text { Communities of Practice } \\
\text { are "Groups of people } \\
\text { who share a concern or a } \\
\text { passion for something } \\
\text { they do and learn how to } \\
\text { do it better as they } \\
\text { internat regrly" }\end{array}$ & $\begin{array}{l}\text { This theory supports } \\
\text { experiential education as } \\
\text { a means of developing } \\
\text { PIF, wherein students } \\
\text { begin to construct an } \\
\text { identity as a pharmacist } \\
\text { through active } \\
\text { participation in the } \\
\text { practice of pharmacy. } \\
\text { Reliance on external } \\
\text { preceptors may hinder } \\
\text { PIF, if the environment } \\
\text { portrays negative views } \\
\text { of the profession or } \\
\text { inculcates undesired } \\
\text { behaviors. }\end{array}$ & $\begin{array}{l}\text { This model will be } \\
\text { intuitive and feel familiar } \\
\text { to most educators. The } \\
\text { model recognizes the } \\
\text { importance of symbols, } \\
\text { rituals, language, and } \\
\text { other professional } \\
\text { milestones in the } \\
\text { socialization process. } \\
\text { However, this model } \\
\text { offers little guidance } \\
\text { regarding assessment or } \\
\text { pedagogy beyond role } \\
\text { modeling and reflection } \\
\text { and focuses more on the } \\
\text { system than the } \\
\text { individual. }\end{array}$ \\
\hline $\begin{array}{l}\text { Explores the question: } \\
\text { "How do individuals } \\
\text { identify and describe } \\
\text { social groups and } \\
\text { create a sense of } \\
\text { belonging?" }\end{array}$ & $\begin{array}{l}\text { Social identity is a person's } \\
\text { sense of who they are based on } \\
\text { their group membership(s). It } \\
\text { allows individuals to compare } \\
\text { themselves to others and may } \\
\text { generate "us vs them" } \\
\text { categorization mentalities as } \\
\text { part of normal human } \\
\text { psychology. Individuals first } \\
\text { categorize or label groups, then } \\
\text { determine their "fit" within a } \\
\text { group and compare and rank } \\
\text { their group against others. }\end{array}$ & $\begin{array}{l}\text { Individuals stereotype } \\
\text { other people and groups } \\
\text { as a normal cognitive } \\
\text { process that tends to } \\
\text { emphasize the positive } \\
\text { traits and similarities of } \\
\text { persons within the same } \\
\text { group while } \\
\text { simultaneously } \\
\text { exaggerating differences } \\
\text { between groups, } \\
\text { solidifying the group's } \\
\text { cohesive social identity. }\end{array}$ & $\begin{array}{l}\text { A sense of belonging and } \\
\text { fit within a group that } \\
\text { allows for ego, pride, and } \\
\text { self-esteem. Strong } \\
\text { identity can also lead to } \\
\text { prejudice or racism if } \\
\text { groups are seen to be in } \\
\text { competition with one } \\
\text { another. }\end{array}$ & $\begin{array}{l}\text { Students must develop a } \\
\text { sense of belonging } \\
\text { within the profession in } \\
\text { order to develop a } \\
\text { professional identity. } \\
\text { Acknowledging } \\
\text { prejudiced views arising } \\
\text { from social comparison } \\
\text { are important areas of } \\
\text { conversation for } \\
\text { Interprofessional } \\
\text { Education and the } \\
\text { equity, diversity, and } \\
\text { social justice movement. }\end{array}$ & $\begin{array}{l}\text { Social Identity Theory } \\
\text { describes how group } \\
\text { members will naturally } \\
\text { seek to find negative } \\
\text { aspects of other groups, } \\
\text { thus enhancing their own } \\
\text { self-image. Educators } \\
\text { should encourage students } \\
\text { to identify potential areas } \\
\text { of prejudice or } \\
\text { discrimination and to } \\
\text { support and value } \\
\text { teamwork, collaboration, } \\
\text { empathy, and inclusion. }\end{array}$ \\
\hline
\end{tabular}




\section{Identity Formation \\ Theories}

Foundational Concepts

Over their lifetimes

Self-Authorship

Theory \& Learning

Partnerships Model $^{24}$

Explores the questions:

"To what extent does an individual define

their own values and beliefs? And how does one develop a greater internal influence?"

\section{Provisional-Selves $^{27}$}

Explores the question: "How does an individual imitate and experiment with different identity traits to determine a good fit?" individuals progress through four distinct named phases representing the extent of external influence on knowledge, beliefs, and decision-making. Self-

Authored individuals have transitioned from external to internal motivation within 3 domains: Cognitive (how do know?), Intrapersonal (who am I?), Interpersonal (how do I want to relate to others?)

Changes in an individual's role are accompanied by changes in their professional identity. Individuals observe role models and experiment with "provisional selves" to emulate traits and behaviors until experience shows which style fits best with their new situation. Students self-reflect to evaluate their experiences

\section{Trigger/Stimulus}

End Goal

Application in PIF

Benefits/Limitations
"Provocative moments" Self-authorship against internal standards and expectations and use

feedback from external sources to determine a final identity fit. structured according to the pedagogical Learning can cause students to shift towards greater internal reliance.

Requirements of the LPM include:

1. Validating learners' capacity to know,

\section{Situating learning in} learners' experiences,

3. Mutually constructing meaning as peers.

Individuals utilize imitation as one possible strategy for exploring alternate selves.

"By rehearsing these clumsy, often ineffective, sometimes inauthentic selves, they learned more about the limitations and potential of their repertoires and thus began to make decisions about what elements to keep, refine, reject, or continue to search for." individuals have "an ability to construct

knowledge in a contextual world, an ability to construct an internal identity separate from external influences, and an ability to engage in

relationships without losing one's internal identity."

Individuals progress towards acquisition of behavioral skills (eg, dress, mannerisms, and professional style) by experimenting with characteristics in order to determine their own valued traits based on positive outcomes from lived experiences and internal and external feedback.
This theory supports cocurricular education as a means of developing PIF wherein students may experience a provocative moment that triggers identity growth during challenging, meaningful, lived experiences where students are in control of their actions and are learning in partnership with peers and role models.

This theory supports mentoring relationships as a means of developing PIF wherein students engage with role models embodying different professional traits and receive both intentional and subconscious formative feedback on their attempts to employ different identity characteristics (attitudes, mannerisms) or participate in social rituals (greetings, use of profanity).
This theory allows for categorization of individuals into "maturity levels" according to their "ways of knowing" which may eventually lead to quantitative assessment tools.

This theory offers a strong pedagogical model educators can utilize to

design provocative learning experiences intended to advance growth and identity formation.

This theory describes how individuals "try on" professional traits prior to adopting them, which may be more consistent with behavior-based professionalism frameworks than with PIF. The theory includes "evaluating experiences" as an important step in determining whether to adopt a trait, suggesting reflection and the learnereducator relationship are critical to PIF. 


\section{Scenario}

\section{"We all have blindspots"}

Passing a group of students in the hallway following class, you overhear that a colleague's course is irrelevant. One student reports, "I've been working in pharmacy for 7 years and I've never had to use this kind of information.'

\section{"Change can be scary"}

In discussing their internship, a 2nd year student comments that they "don't know if pharmacy is right for them." When prompted, the student indicates that they don't "fit in" with the technicians at their internship site. They are also reluctant to work more closely with the pharmacists due to feelings of inadequacy.

\section{"Losing the training wheels"} During the final week of a clinical APPE, after modeling and allowing increasing student autonomy, the preceptor peripherally observes the student during rounds. The preceptor notes the student has established rapport with the interdisciplinary team and makes unprompted suggestions on ways to optimize pharmacotherapy and enhance the delivery of patient care.

\section{Barriers and Contributors to Identity Formation}

The student overestimates their expertise (unconscious incompetence), resulting in stereotyping the profession and failure to recognize possible pharmacist identity roles beyond their personal experience. This scenario may illustrate dissonance between student and faculty expectations for professional identity.

The student recognizes they have not yet adopted a strong professional identity as a pharmacist and therefore lacks a sense of belonging within the community. The student fails to make connections between experimentation and adoption of identity within a role, as described in the Provisional Selves $^{27}$ model of identity development.

The preceptor first models and then facilitates the student's ability to "think, act, and feel" like a pharmacist. The preceptor provides high quality, criterionbased formative feedback to the student throughout the transition, explaining and re-iterating professional values, norms, and performance standards.
Example Connections to
Identity Formation Theory

Social Identity Theory ${ }^{23}$

describes how a strong sense of belonging within a group leads to pride and membership self-

esteem, but risks stereotyping and prejudice against other groups

values and beliefs. In our scenario the student strongly identifies with a particular role which results in failure to recognize value in other knowledge, skills, and identity roles.

\section{Communities of Practice ${ }^{22}$}

require legitimate participation in a group's activities in order to stimulate the sense of belonging within a group and adoption of identity roles. Increasing participation is rewarded with increased sense of belonging and responsibility within the group, as well as increased competence and effectiveness with roles and skills.

Student displays progress towards Self-Authorship ${ }^{24}$ with limited reliance on external authority figures in decision-making. Student has advanced towards greater self-confidence and internal motivation by successfully engaging in (and adapting to) challenging and meaningful lived experiences with the support and guidance of role models.
Examples of a Pedagogical Approach for Faculty Members (environment, activities)

Educators could encourage students to identify their own bias and prejudice and explore alternate perspectives through reflection or debate.

Early exposure to concepts of practice transformation, legislative advocacy, and career counseling may support open-mindedness in student perceptions of the ever-changing role of the pharmacist.

Teach students about the process of PIF, including the components and process of Communities of Practice. Discuss elements of pharmacist identity to help students feel more comfortable with the process of transitioning between identities. Practice sharing your own experiences and vulnerabilities with learners.

Provide early safe opportunities for students to mimic the role of the pharmacist and develop competence in basic skills and tools through shadowing,

compounding laboratories, simulated experiences, standardized patient encounters, OSCEs, etc.

\section{Utilize the Learning Partnerships $\mathrm{Model}^{24}$ to}

deliberately reduce the educators' role as an external authority and increase student autonomy in learning and practice.

Engage in the four precepting roles ${ }^{37}$ (instructing, modeling, coaching, and facilitating) and provide criterion-based feedback to intentionally and progressively support students' transition to professionals.

Require and model guided discussion and reflection on identity roles and dimensions. 
Figure 1. Description Of Key Elements of Professional Identity Formation During Pharmacy Education ${ }^{\mathrm{a}}$

Previous experiences (culture, education, socioeconomic status, etc.)

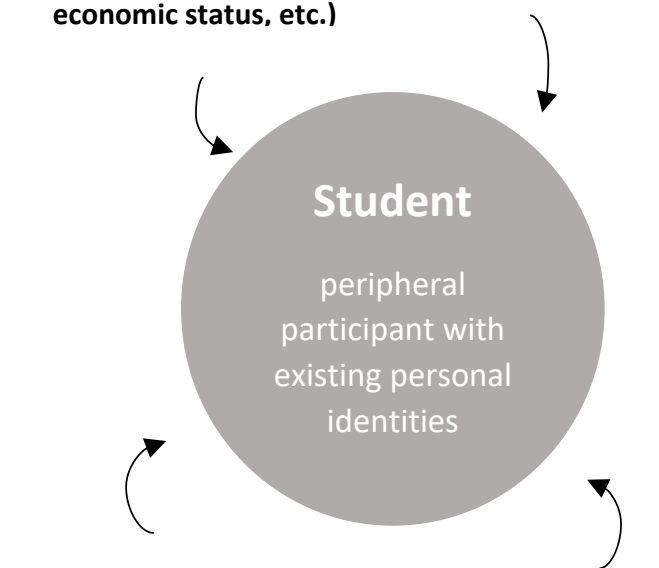

Family, friends,

peers, and

community (gender identity,
Existing identities race, ethnicity, etc)

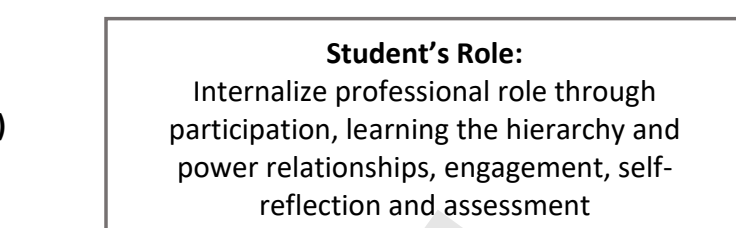

Professional Identity Formation

A fluid and evolving life-long process where you 'pretend before you become' by way of

socialization \& communities of practice ${ }^{c}$

(conscious reflection \& unconscious acquisition)

\section{Educator's Role: ${ }^{\text {b }}$}

Role model, establish intentional educational

activities and feedback to support

socialization, integrate students within the

community of practice through mentoring and

experiential learning

${ }^{a}$ Schematic inspired by Cruess. Cruess, Boudreau, Snell \& Steinert (2015) and Cruess \& Cruess (2019)

${ }^{\mathrm{b}}$ Educator refers to all individuals who influence identity formation of the learner across various disciplines and settings.

${ }^{\mathrm{c}}$ Other models/theories of personal identity development (eg, self-authorship theory, self-determination theory) can also be adopted.

${ }^{\mathrm{d}}$ The PIF process continues past graduation or licensure as a pharmacist. 